\title{
The First Hydroxylated Archazolid from the Myxobacterium Cystobacter violaceus: Isolation, Structural Elucidation and V-ATPase Inhibition
}

\author{
Dirk Menche, Jorma Hassfeld, Heinrich Steinmetz, Markus Huss, Helmut Wieczorek, \\ Florenz Sasse
}

Received: March 20, 2007 / Accepted: May 1, 2007

(C) Japan Antibiotics Research Association

\begin{abstract}
The novel macrocyclic polyketide, 10hydroxymethyl-archazolid-7- $O$ - $\beta$-D-glucopyranoside (archazolid D), was obtained from the myxobacterium Cystobacter violaceus. The structure of this first hydroxylated archazolid was determined by spectroscopic analysis, in particular by HMBC, HMQC, and ROESY NMR investigations, and by degradation. This novel metabolite was evaluated for growth inhibition of murine connective tissue cells and V-ATPase inhibition in comparison to other known archazolids.
\end{abstract}

Keywords polyketide, V-ATPase inhibition, archazolid, myxobacterium, Cystobacter violaceus

The development and molecular understanding of inhibitors for vacuolar-type ATPases (V-ATPases) presents an important research goal, as the functionality of these heteromultimeric, proton transporting proteins is associated with various diseases such as osteoporosis, renal acidosis and cancer [1]. The macrolide antibiotics archazolid A (1, Fig. 1) and B (2) [2] are a structurally novel type of

D. Menche (Corresponding author), J. Hassfeld, H. Steinmetz, F. Sasse: Helmholtz-Zentrum für Infektionsforschung $\mathrm{GmbH}$ (recently renamed from Gesellschaft für Biotechnologische Forschung mbH), Medicinal Chemistry and Chemical Biology, Inhoffenstr. 7, 38124 Braunschweig, Germany,

E-mail: dirk.menche@helmoltz-hzi.de

M. Huss, H. Wieczorek: Universität Osnabrück, Fachbereich Biologie/Chemie, Abteilung Tierphysiologie, 49069 Osnabrück, Germany particularly efficient V-ATPase inhibitors with $\mathrm{IC}_{50}$ values in the low nanomolar range, both in vitro [3] and in vivo [2]. It has been demonstrated that $\mathbf{1}$ binds to the membrane bound $\mathrm{V}_{\mathrm{o}}$ subunit $\mathrm{c}$ in a reversible non-covalent manner [3]. This subunit forms an oligomer, building up a ring structure of six or more copies which transports protons across the membrane. Recently, the structure of the ring from a bacterial V-ATPase has been described at $2.1 \AA$ resolution and showed that 10 copies form the c ring [4]. This increasing molecular understanding in combination with the very promising biological profile of the archazolids renders these macrolide antibiotics attractive structures for further development. Very recently, the full stereochemistry of the archazolids has been determined by extensive NMR studies and chemical derivatization [5], and was confirmed by total synthesis [6]. So far, however, only very limited SAR-data are available, relying on modifications of the hydroxyl groups at C-7, C-15 and C-1' $[7,8]$. Herein, we describe the isolation and structure elucidation of the first archazolid with a modified carbon backbone, the hydroxylated derivative 10-hydroxymethylarchazolid-7- $O$ - $\beta$-D-glucopyranoside (archazolid D, 4), from fermentation broths of the myxobacterium Cystobacter violaceus and report on the V-ATPase inhibitory effect of this novel macrolide antibiotic in comparison to other known V-ATPase inhibitors.

In a screening for novel and more efficient archazolid producing myxobacteria, we have recently identified $C$. violaceus strain $\mathrm{Cb}$ vi105 as the natural source of the first archazolid glycoside, archazolid-7- $O$ - $\beta$-D-glucopyranoside (archazolid C, 3, Fig. 1), which was obtained as the major metabolite from fermentation broths together with the parent compound archazolid A. A detailed analysis of this 

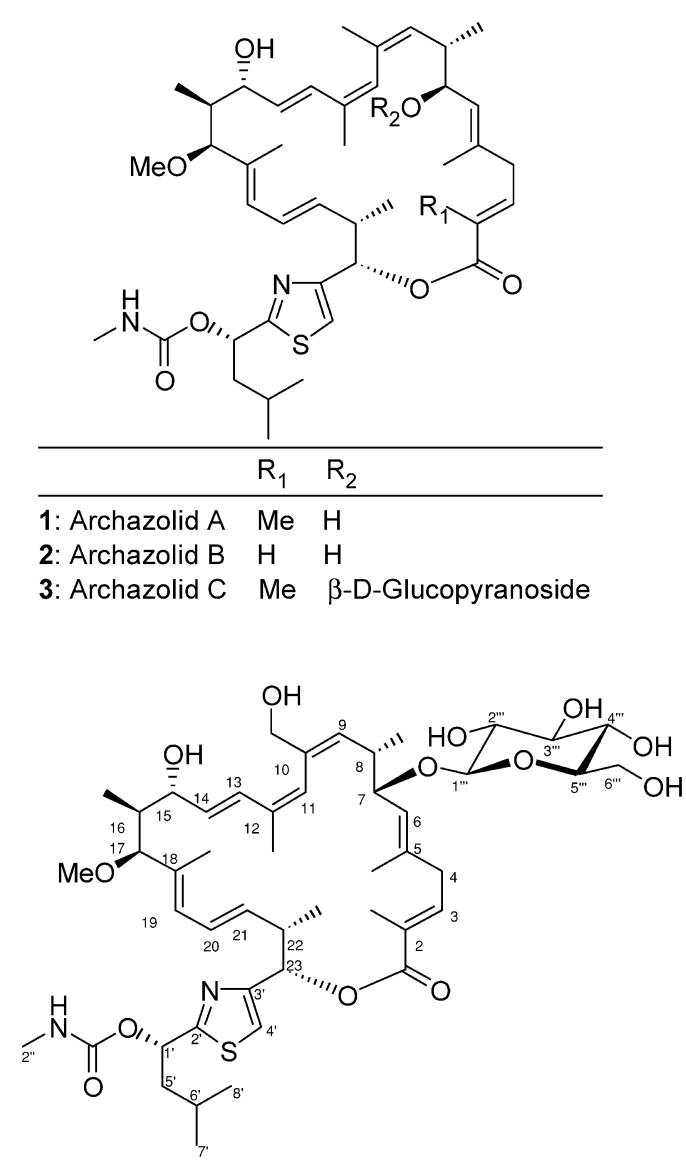

\section{4: 10-Hydroxymethyl-archazolid-7-O- $\beta$-D-glucopyranoside (Archazolid D)}

Fig. 1 The archazolids: potent V-ATPase inhibitors from myxobacteria.

extract for trace metabolites by LC-MS in combination with UV-VIS spectra suggested one further archazolid derivative to be present in traces, i.a. by a characteristic UV maximum around $230 \mathrm{~nm}$. As this metabolite was only produced in minute amounts $(<0.03 \mathrm{mg} /$ liter $)$, a 300 -liter bioreactor of $C$. violaceus strain $\mathrm{Cb}$ vi105 was run. Fermentation was performed in the presence of 3 liters Amberlite XAD for absorption of excreted secondary metabolites. After 10 days, the adsorber resin and cell mass $(4.9 \mathrm{~kg})$ were obtained by centrifugation and subsequently extracted with acetone to give $13.7 \mathrm{~g}$ of crude extract. Consecutive gel chromatography (Sephadex LH-20), MPLC and reversed-phase HPLC yielded $4.2 \mathrm{mg}$ of the novel derivative.

The ${ }^{1} \mathrm{H}$ NMR data of $\mathbf{4}$, as shown in Table 1, revealed a similar pattern to that of the known archazolids: Ten oneproton signals in the unsaturated region with the expected coupling constants for $11-\mathrm{H}, 4^{\prime}-\mathrm{H}, 6-\mathrm{H}, 9-\mathrm{H}, 13-\mathrm{H}, 19-\mathrm{H}$, $3-\mathrm{H}, 14-\mathrm{H}, 20-\mathrm{H}$ and $21-\mathrm{H}$ and five further low-field
Table $1{ }^{1} \mathrm{H}$ - and ${ }^{13} \mathrm{C}$-NMR data for 10-hydroxymethylarchazolid-7-O- $\beta$-D-glucopyranoside $(\mathbf{3})^{\mathrm{a}}$

\begin{tabular}{|c|c|c|}
\hline No. & ${ }^{13} C^{b}$ & ${ }^{1} \mathrm{H}$ mult., $J(\mathrm{~Hz})$ \\
\hline 1 & 168.4 & - \\
\hline 2 & 130.1 & - \\
\hline 3 & 142.1 & $6.76 t, 7.4$ \\
\hline 4 & 40.9 & $2.84 \mathrm{~m} / 3.06 \mathrm{dd}, 14.0,9.4$ \\
\hline 5 & 136.2 & - \\
\hline 6 & 131.0 & $5.21 d, 9.1$ \\
\hline 7 & 74.0 & 4.09 t, 9.63 \\
\hline 8 & 40.4 & $2.38 \mathrm{ddq}, 9.4,9.1,6.8$ \\
\hline 9 & 133.9 & $5.59 d, 9.8$ \\
\hline 10 & 138.0 & - \\
\hline 11 & 127.4 & $5.76 \mathrm{~s}$ \\
\hline 12 & 133.3 & - \\
\hline 13 & 131.2 & $6.94 \mathrm{br} \mathrm{m}$ \\
\hline 14 & 131.0 & $5.66 \mathrm{~d}, 12.8$ \\
\hline 15 & 74.3 & 4.70 br s \\
\hline 16 & 42.8 & $1.73 \mathrm{~m}$ \\
\hline 17 & 89.3 & $3.58 \mathrm{~m}$ \\
\hline 18 & 135.9 & - \\
\hline 19 & 131.0 & $5.88 d, 10.9$ \\
\hline 20 & 127.2 & $6.25 \mathrm{t}, 12.6$ \\
\hline 21 & 134.7 & $5.63 \mathrm{~m}$ \\
\hline 22 & 41.0 & $3.16 \mathrm{brm}$ \\
\hline 23 & 73.5 & $6.03 \mathrm{brs}$ \\
\hline $2-\mathrm{CH}_{3}$ & 12.9 & $1.93 \mathrm{~s}$ \\
\hline $5-\mathrm{CH}_{3}$ & 16.7 & $1.73 \mathrm{~s}$ \\
\hline $8-\mathrm{CH}_{3}$ & 17.5 & $0.82 \mathrm{~d}, 6.4$ \\
\hline $10-\underline{\mathrm{H}}_{2} \mathrm{OH}$ & 68.2 & $3.93 \mathrm{~d}, 12.8 / 4.04 \mathrm{~d}, 12.8$ \\
\hline $12-\mathrm{CH}_{3}$ & 19.9 & 1.97 \\
\hline $16-\mathrm{CH}_{3}$ & 12.5 & $0.74 d, 7.2$ \\
\hline $17-\mathrm{OCH}_{3}$ & 56.4 & $3.20 \mathrm{~s}$ \\
\hline $18-\mathrm{CH}_{3}$ & 11.8 & $1.65 \mathrm{~s}$ \\
\hline $22-\mathrm{CH}_{3}$ & 16.9 & $1.23 \mathrm{~d}, 6.8$ \\
\hline $1^{\prime}$ & 77.7 & $6.03 \mathrm{dd}, 8.3,4.5$ \\
\hline $2^{\prime}$ & 174.3 & - \\
\hline $3^{\prime}$ & 156.3 & - \\
\hline $4^{\prime}$ & 116.4 & $7.15 \mathrm{~s}$ \\
\hline $5^{\prime}$ & 46.1 & $1.84 / 1.96$ \\
\hline $6^{\prime}$ & 26.5 & $1.81 \mathrm{~m}$ \\
\hline $7^{\prime}$ & 22.5 & $1.03 \mathrm{~d}, 6.0$ \\
\hline $8^{\prime}$ & 23.5 & $1.03 \mathrm{~d}, 6.0$ \\
\hline $1^{\prime \prime}$ & 158.2 & - \\
\hline $2^{\prime \prime}$ & 27.7 & $2.75 \mathrm{~s}$ \\
\hline $1^{\prime \prime \prime}$ & 102.2 & 4.23 d, 7.9 \\
\hline $2^{\prime \prime \prime}$ & 75.5 & $3.29 \mathrm{dd}, 8.3,7.9$ \\
\hline $3^{\prime \prime \prime}$ & 77.9 & $3.34 \mathrm{~m}$ \\
\hline $4^{\prime \prime \prime}$ & 71.9 & $3.38 \mathrm{~m}$ \\
\hline $5^{\prime \prime \prime}$ & 77.8 & $3.21 \mathrm{~m}$ \\
\hline $6^{\prime \prime \prime}$ & 62.8 & $3.74 \mathrm{dd}, 11.5,5.1 / 3.86 \mathrm{dd}, 11.5,2.5$ \\
\hline
\end{tabular}

a Spectra were recorded in $\mathrm{CD}_{3} \mathrm{OD}$ at $600\left({ }^{1} \mathrm{H} \mathrm{NMR}\right)$ and $150 \mathrm{MHz}\left({ }^{13} \mathrm{C}\right)$.

${ }^{\mathrm{b}}$ The ${ }^{13} \mathrm{C}$ assignments were achieved by $\mathrm{HMOC}$ and $\mathrm{HMBC}$ experiments. 
protons for $7-\mathrm{H}, 15-\mathrm{H}, 17-\mathrm{H}, 23-\mathrm{H}$ and $1^{\prime}-\mathrm{H}$ together with further one-proton signals in the aliphatic region (chemical shift $=3 \mathrm{ppm}$ ) for the macrocyclic protons $4 \mathrm{a}-\mathrm{H}, 4 \mathrm{~b}-\mathrm{H}, 8-\mathrm{H}$, $16-\mathrm{H}, 22-\mathrm{H}, 5^{\prime}-\mathrm{H}$ and $6^{\prime}-\mathrm{H}$ indicated a poly-unsaturated backbone closely related to 1 . Remaining ${ }^{1} \mathrm{H}$ NMR signals were observed in the region from $\delta 3.00$ to 4.00 , which were very similar to those of $\mathbf{3}$ and likewise suggested the presence of a hexose substituent. The $O$-glycosidic nature of this compound became also evident from a doublet at $\delta$ $4.23(7.9 \mathrm{~Hz})$, attributed to an anomeric proton $\left(1^{\prime \prime \prime}-\mathrm{H}\right)$. The signals for $2^{\prime \prime \prime}-\mathrm{H}$ to $5^{\prime \prime \prime}-\mathrm{H}$ were resolved in $\mathrm{CD}_{3} \mathrm{OD}$ and assigned to glucose. The ${ }^{13} \mathrm{C}$ NMR data displayed also the expected number of carbons and chemical shifts for glucose [9], which was further confirmed by ROESY interactions and ultimately proven by acidic hydrolysis and detection as the per-TMS-silylated methyl-glycoside by GC-comparison according to the method of Chaplin [10]. The position of the glucose unit was deduced by ROESY experiments (interactions of $1^{\prime \prime \prime}-\mathrm{H}$ with $7-\mathrm{H}$ and $8-\mathrm{H}$ ) and by a long-range $\mathrm{C}-\mathrm{H}$ correlation from $\left(1^{\prime \prime \prime}-\mathrm{H}\right.$ to $\left.\mathrm{C}-7\right)$. Therefore, the sugar unit is situated at position O-7.

The molecular ion peak for the novel metabolite was observed at $\mathrm{m} / \mathrm{z} 916$, which is 16 mass units higher than that of $3(\mathrm{MW}=900)$ and hinted at the presence of an additional oxygen atom. Furthermore, a noticeable difference in the proton NMR spectrum of $\mathbf{4}$ was the absence of one three-proton signal for an allylic methyl group. Only four-instead of five-singlets (/doublets with a small w-coupling constant of smaller than $2 \mathrm{~Hz}$ ) at $\delta=1.93$, $1.73,1.97$ and 1.65 were observed, which were assigned to the allylic methyl groups at C-2, C-5, C-12 and C-18 by COSY and HMBC correlations. These data suggest that $\mathbf{4}$ is an oxygenated archazolid and contains an allylic hydroxymethyl group. Based on HMBC and ROESY correlations, this hydroxymethyl group is situated at C-10, and the new hydroxylated archazolid has the constitution shown in Fig. 2. Its structure was further confirmed by TOCSY experiments and HMBC and HMQC interactions. For the new hydroxylated archazolid, we suggest the name archazolid D. The close similarity of the spectroscopic data of $\mathbf{4}$ to $\mathbf{3}$ suggests this novel analogue to reside in a solution conformation closely related to that of the other archazolids $[5,7]$.

For biological evaluation of the novel analogue, first the inhibitory effect on the growth of the murine connective tissue cell line L-929 was tested. As expected for a 7-Osubstituted analogue, 4 was less potent $\left(\mathrm{IC}_{50}=330 \mathrm{nM}\right)$ as compared to the parent natural products $\mathbf{1}$ and $\mathbf{2}\left(\mathrm{IC}_{50}=\right.$ $0.81 / 1.1 \mathrm{nM}$ ), however it was 5 times more active than the corresponding non-hydroxylated congener $3\left(\mathrm{IC}_{50}=1600\right.$ $\mathrm{nM})$. This similarity in biological activity already suggested that 4, like other members of the archazolid family, should target V-ATPases. Indeed, by using established procedures it was shown that the purified V-ATPase holoenzyme from the midgut of the tobacco hornworm was inhibited with an $\mathrm{IC}_{50}$ value of $1.2 \mu \mathrm{mol} / \mathrm{mg}$ enzyme $[7,11,12]$. Thus, 4 is much less inhibitory than $\mathbf{1}$ and $\mathbf{2}$ with an $\mathrm{IC}_{50}$ value of $0.6 \mathrm{nmol} / \mathrm{mg}$ enzyme. Nevertheless it inhibits the VATPase, albeit in the micromolar instead of the nanomolar range.

In summary, we have reported the first hydroxylated archazolid, 10-hydroxymethyl-archazolid-7- $O$ - $\beta$-D-glucopyranoside (named archazolid D, 4) from the myxobacterium C. violaceus. As compared to 1 and 2, 4 exhibits only moderate activity against the V-ATPase in vitro and in vivo. However, in the cell culture assays it was shown to be more potent than the corresponding non-hydroxylated analogue, $\mathbf{3}$. These results suggest that it might be possible to increase the potency of the non-glycosylated archazolids by structural modifications of the macrocyclic backbone and makes it very rewarding to develop synthetic analogues along these lines.

\section{Experimental}

\section{General Experimental Procedures}

Optical rotations were determined on a Perkin-Elmer 241 instrument. UV spectra were recorded on a Shimadzu UV2102 PC scanning spectrometer. IR spectra were measured with a Nicolet 20DXB FT-IR spectrometer. NMR spectra were recorded in $\mathrm{CD}_{3} \mathrm{OD}$ on a Bruker DMX-600 spectrometer. EI and DCI mass spectra (reactant gas ammonia) were obtained on a Finnigan MAT 95 spectrometer, high resolution data were aquired using peak matching $(\mathrm{M} / \mathrm{DM}=10000)$. Pure compounds were characterized by analytical HPLC on Nucleodur C 18 (column $125 \times 2 \mathrm{~mm}, 5 \mu \mathrm{m}$, methanol/water $=82: 18$, flow $0.3 \mathrm{ml} /$ minute, diode array detection). The retention times for $\mathbf{1}, \mathbf{3}$ and $\mathbf{4}$ were 11.8, 6.3 and 4.8 minutes.

\section{Production of the Novel Archazolid 4}

Fermentation of $C$. violaceus strain $\mathrm{Cb}$ vi105, isolated at the HZI, in the presence of 3 liter Amberlite XAD-16 adsorber resin for 10 days at $30^{\circ} \mathrm{C}$ and preparation of the crude extract $(13.7 \mathrm{~g})$ from the adsorber resin proceeded according to previously reported procedures $[2,7] .4$ was isolated and purified from the crude extract by gel chromatography on Sephadex LH 20 (Fluka Steinheim, solvent: methanol, flow $7 \mathrm{ml} /$ minute), reversed-phase MPLC (solvent: methanol/water $=8: 2$, detection $230 \mathrm{~nm}$, flow $65 \mathrm{ml} /$ minute) and high pressure RP chromatography 
(solvent: acetonitrile/water $=65 / 35$, detection $230 \mathrm{~nm}$, flow $15 \mathrm{ml} /$ minute). In total, $4.2 \mathrm{mg}$ were obtained.

\section{Physicochemical Properties of 4}

10 -Hydroxymethyl-archazolid-7- $O$ - $\beta$-D-glucopyranoside (archazolid D, 4): colourless amorphous solid; $[\alpha]_{\mathrm{D}}^{22}-26.8^{\circ}$ (c $0.22, \mathrm{MeOH}$ ); IR $v_{\max }$ (film) $\mathrm{cm}^{-1} 3355,2926,1715$, 1080; UV $\lambda_{\max }^{\mathrm{MeOH}} 231 \mathrm{~nm}$; NMR see Table 1; HR-MS $917.4860[(\mathrm{M}+\mathrm{H})]^{+}, \mathrm{C}_{48} \mathrm{H}_{73} \mathrm{~N}_{2} \mathrm{O}_{13} \mathrm{~S}$ requires 917.4833 .

\section{Cell Culture and Growth Inhibition Assay}

The L-929 mouse cell line was from the German collection of Microorganisms and Cell Cultures (DSMZ) and cultivated in DME medium (GIBCO BRL) plus 10\% newborn calf serum at $37^{\circ} \mathrm{C}$ and $10 \% \mathrm{CO}_{2}$ in a moist atmosphere. Growth inhibition was measured on microtiterplates. Aliquots of $120 \mu \mathrm{l}$ of the suspended cells $\left(50,000 \mathrm{ml}^{-1}\right)$ were given to $60 \mu \mathrm{l}$ of a serial dilution of the inhibitor. After 5 days, metabolic activity per well was determined using the MTT assay [13].

Acknowledgements This work was generously supported by the Fonds der Chemischen Industrie ('Liebig-Stipendium' to D.M.) and the Volkswagenstiftung (Funding Initiative: 'Interplay between Molecular Conformations and Biological Function'). In addition, this work was supported by the HZI and the DFG (SFB 431). We thank Tatjana Arnold, Antje Ritter and Bettina Hinkelmann for technical support and the Fermentation Service of the HZI for help with large scale fermentation. Furthermore, we thank Dr. M. Nimtz for GC-MS analysis of glucose.

References

1. Beyenbach KW, Wieczorek H. The V-type $\mathrm{H}^{+}$-ATPase: Molecular structure and function, physiological roles and regulation. J Exp Biol 209: 577-589 (2006)

2. Sasse F, Steinmetz H, Höfle G, Reichenbach H. Archazolids, new cytotoxic macrolactones from Archangium gephyra (myxobacteria). Production, isolation, physico-chemical and biological properties. J Antibiot 56: 520-525 (2003)

3. Huss M, Sasse F, Kunze B, Jansen R, Steinmetz H,
Ingenhorst G, Zeeck A, Wieczorek H. Archazolid and apicularen: Novel specific V-ATPase inhibitors. BMC Biochem 6: 1-13 (2005)

4. Murata T, Yamato I, Kakinuma Y, Leslie AG, Walker JE. Structure of the Rotor of the V-Type $\mathrm{Na}^{+}$-ATPase from Enterococcus. Science 308: 654-657 (2005)

5. Hassfeld J, Farès C, Steinmetz H, Carlomagno T, Menche D. Stereochemical determination of archazolid A and B, highly potent vacuolar-type ATPase inhibitors from the myxobacterium Archangium gephyra. Org Lett 8: 47514754 (2006)

6. Menche D, Hassfeld J, Li J, Rudolph S. Total Synthesis of Archazolid A. J Am Chem Soc, 129: 6100-6101 (2007)

7. Menche D, Hassfeld J, Steinmetz H, Huss M, Wieczorek H, Sasse F. Archazolid-7- $O-\beta$-D-glucopyranosid: Isolation, structural elucidation and solution conformation of a novel V-ATPase inhibitor from the myxobacterium Cystobacter violaceus. Eur J Org Chem 1196-1202 (2007)

8. Menche D, Hassfeld J, Sasse F, Huss M, Wieczorek H. Design, synthesis and biological evaluation of novel analogues of archazolid: a highly potent simplified VATPase inhibitor. Bioorg Med Chem Lett 17: 1732-1735 (2007)

9. Seo S, Tomita Y, Tori K, Yoshimura Y. Determination of the absolute configuration of a secondary hydroxy group in a chiral secondary alcohol using glycosidation shifts in carbon-13 nuclear magnetic resonance spectroscopy. J Am Chem Soc 100: 3331-3339 (1978)

10. Chaplin MF. A rapid and sensitive method for the analysis of carbohydrate components in glycoproteins using gas-liquid chromatography. Anal Biochem 123: 336-341 (1982)

11. Huss M, Ingenhorst G, König S, Gassel M, Dröse S, Zeeck A, Altendorf K, Wieczorek H. Concanamycin A, the specific inhibitor of V-ATPases, binds to the $\mathrm{V}_{\mathrm{o}}$ subunit c. J Biol Chem 277: 40544-40548 (2002)

12. Wieczorek H, Cioffi M, Klein U, Harvey WR, Schweikl H, Wolfersberger MG. Isolation of goblet cell apical membrane from tobacco hornworm midgut and purification of its vacuolar-type ATPase. Methods Enzymol 192: 608-616 (1990)

13. Mosman T. Rapid colorimetric assay for cellular growth and survival: Application. to proliferation and cytotoxicity assays. J Immunol Methods 65: 55-63 (1983) 